\title{
The favorable kinetics and balance of nebivolol-stimulated nitric oxide and peroxynitrite release in human endothelial cells
}

\author{
R Preston Mason ${ }^{1,2}$, Robert F Jacob², J Jose Corbalan ${ }^{3}$, Damian Szczesny ${ }^{3}$, Kinga Matysiak ${ }^{3}$ and Tadeusz Malinski ${ }^{3^{*}}$
}

\begin{abstract}
Background: Nebivolol is a third-generation beta-blocker used to treat hypertension. The vasodilation properties of nebivolol have been attributed to nitric oxide (NO) release. However, the kinetics and mechanism of nebivololstimulated bioavailable NO are not fully understood.

Methods: Using amperometric $\mathrm{NO}$ and peroxynitrite (ONOO) nanosensors, $\beta_{3}$-receptor (agonist: L-755,507; antagonists: SR59230A and L-748,337), ATP efflux (the mechanosensitive ATP channel blocker, gadolinium) and P2Y-receptor (agonists: ATP and 2-MeSATP; antagonist: suramin) modulators, superoxide dismutase and a NADPH oxidase inhibitor (VAS2870), we evaluated the kinetics and balance of $\mathrm{NO}$ and $\mathrm{ONOO}^{-}$stimulated by nebivolol in human umbilical vein endothelial cells (HUVECs). $\mathrm{NO}$ and $\mathrm{ONOO}^{-}$were measured with nanosensors (diameter $~ 300 \mathrm{~nm}$ ) placed $5 \pm 2 \mu \mathrm{m}$ from the cell membrane and ATP levels were determined with a bioluminescent method. The kinetics and balance of nebivolol-stimulated $\mathrm{NO}$ and $\mathrm{ONOO}^{-}$were compared with those of ATP, 2-MeSATP, and L-755,507.
\end{abstract}

Results: Nebivolol stimulates endothelial NO release through $\beta_{3}$-receptor and ATP-dependent, P2Y-receptor activation with relatively slow kinetics $(75 \pm 5 \mathrm{nM} / \mathrm{s})$ as compared to the kinetics of ATP $(194 \pm 10 \mathrm{nM} / \mathrm{s}), \mathrm{L}-755,507(108 \pm 6 \mathrm{nM} / \mathrm{s})$, and 2-MeSATP (105 $\pm 5 \mathrm{nM} / \mathrm{s})$. The balance between cytoprotective $\mathrm{NO}$ and cytotoxic ONOO was expressed as the ratio of $[\mathrm{NO}] /[\mathrm{ONOO}]$ concentrations. This ratio for nebivolol was $1.80 \pm 0.10$ and significantly higher than that for ATP $(0.80 \pm 0.08), L-755,507(1.08 \pm 0.08)$, and 2-MeSATP $(1.09 \pm 0.09)$. Nebivolol induced ATP release in a concentrationdependent manner.

Conclusion: The two major pathways (ATP efflux/P2Y receptors and $\beta_{3}$ receptors) and several steps of nebivololinduced $\mathrm{NO}$ and $\mathrm{ONOO}^{-}$stimulation are mainly responsible for the slow kinetics of $\mathrm{NO}$ release and low ONOO- The net effect of this slow kinetics of $\mathrm{NO}$ is reflected by a favorable high ratio of [NO]/[ONOO$]$ which may explain the beneficial effects of nebivolol in the treatment of endothelial dysfunction, hypertension, heart failure, and angiogenesis.

Keywords: Nevibolol, Nitric oxide, Peroxynitrite, ATP, $\beta_{3}$-adrenergic receptors, P2Y-purinergic receptors

\section{Background}

Arterial endothelial cells modulate vascular tone through release of nitric oxide $(\mathrm{NO})$, a potent vasodilator that regulates regional blood flow [1,2]. Beyond vasodilation, NO has various vascular benefits that reduce the risk for cardiovascular disease. NO inhibits smooth muscle cell proliferation and migration, adhesion of leukocytes to the vascular endothelium, and platelet aggregation [3].

\footnotetext{
*Correspondence: malinski@ohio.edu

${ }^{3}$ Department of Chemistry and Biochemistry, Ohio University, 45701 Athens, $\mathrm{OH}$, USA

Full list of author information is available at the end of the article
}

An uncoupling of endothelial nitric oxide synthase (eNOS) along with reduced endothelial-dependent NO release and generation of peroxynitrite $\left(\mathrm{ONOO}^{-}\right)$has been linked to atherogenesis and its clinical manifestations $[4,5]$. Agents that enhance NO bioavailability have been shown to reduce cardiovascular events, as well as central arterial blood pressure, in patients with hypertension $[4,5]$. NO generation in the endothelium is accompanied by the production of $\mathrm{ONOO}^{-}$. Peroxynitrite, a major component of nitroxidative stress, is cytotoxic and can trigger a cascade of events leading to vasoconstriction, dysfunction of the endothelium, and apoptosis

\section{Biomed Central}

(c) 2013 Mason et al.; licensee BioMed Central Ltd. This is an open access article distributed under the terms of the Creative Commons Attribution License (http://creativecommons.org/licenses/by/2.0), which permits unrestricted use, distribution, and reproduction in any medium, provided the original work is properly cited. 
[6]. Therefore, a change in the balance between $\mathrm{NO}$ and $\mathrm{ONOO}^{-}$generated by the endothelium can significantly affect the endothelial function, and as a result, lead to the dysfunction of the cardiovascular system.

ATP, which widely regulates cell and tissue function through autocrine or paracrine stimulation of purinergic (P2Y) receptors, has also been shown to be an important mediator of endothelial-dependent NO [7]. The vascular effect of ATP was first characterized in aortic segments from spontaneously hypertensive rats, as well as normotensive Wistar-Kyoto rats, in which direct application of ATP caused NO-mediated relaxation [8]. Similar effects were observed in hepatic arterial tissue isolated from New Zealand White rabbits and shown to be dependent on endothelial P2Y receptors [9]. In renal tissue, isolated from Wistar-Kyoto rats, ATP was further shown to induce relaxation of the glomerular microvasculature by activating P2Y receptors, followed by eNOS and guanylate cyclase pathway activation [10].

Nebivolol is a third-generation, $\beta_{1}$-adrenergic receptor antagonist with vasodilatory properties that appear to be independent of its $\beta_{1}$-receptor interactions [11-13]. Its mechanism of action is attributed to eNOS activation since its vasodilatory effects can be reversed with specific eNOS inhibitors such as $\mathrm{N}^{\mathrm{G}}$-monomethyl-L-arginine (L-NMMA) and $\mathrm{N}_{\omega}$-nitro-L-arginine methyl ester (LNAME) [14-16]. In a number of independent studies, nebivolol-induced NO release has also been linked to $\beta_{3^{-}}$ receptor interactions as well as ATP-dependent, P2Ymediated eNOS activation [17-20]. Nebivolol has also been reported to reverse eNOS uncoupling and interfere with oxidative stress processes, by reducing NADPH oxidase activity or by directly scavenging oxygen-derived free radicals [13,20-23].

We conducted this study to evaluate simultaneously the kinetics of nebivolol-stimulated $\mathrm{NO}$ and $\mathrm{ONOO}^{-}$ production and the role of ATP efflux along with P2Yand $\beta_{3}$-receptor activation in human endothelial cells. We hypothesized that the slow kinetics of NO release in the endothelium, through integrated cellular mechanism that include both the ATP autocrine and/or paracrine pathway and these specific receptors, may be at least partially responsible for favorable balance between bioavailable $\mathrm{NO}$ and cytotoxic $\mathrm{ONOO}^{-}$. The high level of $\mathrm{NO}$ and low $\mathrm{ONOO}^{-}$generated by nebivolol may explain its pleiotropic and therapeutic effects on the restoration of endothelial function in the cardiovascular system.

\section{Methods}

\section{Materials}

Nebivolol $\mathrm{HCl}$ (in powder form) was provided by Forest Research Institute (Commack, NY). The $\beta_{3}$-agonist, L755,507, and $\beta_{3}$-antagonists, SR59230A and L-748,337, were purchased from Tocris Bioscience (Ellisville, MO).
ATP, 2-MeSATP, and the non-selective P2Y receptor antagonist, suramin, were purchased from Sigma-Aldrich (St. Louis, MO). Gadolinium $\left(\mathrm{Gd}^{3+}\right)$, a mechanosensitive, ATP-release channel blocker, superoxide dismutase (PEGSOD) and the NADPH oxidase inhibitor, VAS2870, were also purchased from Sigma-Aldrich.

\section{Cell culture}

Primary human umbilical vein endothelial cells (HUVECs) were purchased from Lonza Inc. (Walkersville, MD). Cells were cultured in the recommended complete endothelial cell growth medium and maintained at $37^{\circ} \mathrm{C}$ in a $95 \%$ air / $5 \% \mathrm{CO}_{2}$ humidified incubator. As recommended by the supplier, cells were supplied with fresh medium every other day and propagated by an enzymatic (trypsin) procedure for a maximum of 16 population doublings. Our studies were performed in accordance with the guidelines established by the Ohio University Office of Institutional Research Compliance. These guidelines conform with the principles of the World Medical Association Declaration of Helsinki.

\section{$\mathrm{NO}$ and $\mathrm{ONOO}^{-}$measurement}

Endothelial $\mathrm{NO}$ and $\mathrm{ONOO}^{-}$release was measured using amperometric nanosensors as previously described [21,24]. Briefly, each of the sensors was made by depositing a sensing material on the tip of a carbon fiber (length 4-5 $\mu \mathrm{m}$; diameter 200-300 nm), i.e., a conductive film of polymeric nickel(II)tetrakis(3-methoxy-4-hydroxyphenyl)porphyrin for the NO sensor and a conductive film of polymeric manganese(III)-[2]paracyclophenylporphyrin for the $\mathrm{ONOO}^{-}$ sensor. The fiber was sealed with a nonconductive epoxy and connected to copper electrical wires with a conductive silver epoxy. Confluent HUVECs were rinsed with endothelial basal medium (EBM; Lonza Inc., Walkersville, MD) and the tandem of nanosensors was gently lowered to within $5 \pm 2 \mu \mathrm{m}$ from the surface of an endothelial cell using a remote-controlled micromanipulator (Sensapex, Finland). Amperometric measurements were performed using a Gamry Reference $600^{\mathrm{Tm}}$ dual potentiostat (Gamry instruments, Warminster, PA). Basal $\mathrm{NO}$ and $\mathrm{ONOO}^{-}$ levels were measured by differential pulse voltammetry (DPV) in separate experiments. The DPV current at the peak potential characteristic for $\mathrm{NO}$ and $\mathrm{ONOO}^{-}$is directly proportional to the local concentration of $\mathrm{NO}$ and $\mathrm{ONOO}^{-}$in the immediate vicinity of the sensor. The nanosensors were calibrated before measurements in cells using a linear calibration curve (current versus concentration) constructed from standard $\mathrm{NO}$ or $\mathrm{ONOO}^{-}$solutions ranging from $50 \mathrm{nM}$ to $700 \mathrm{nM}$. The sensors response and calibration was tested again after measurements in cells, using the standard addition method. The detection limit of the sensors was $10^{-9} \mathrm{M}$. 
Changes in current, proportional to the concentration of $\mathrm{NO}$ or $\mathrm{ONOO}^{-}$, were observed after the injection of nebivolol and other agents used in this study, including modulators of the ATP pathway and both agonists and antagonists of the $\beta_{3}$-receptor. To test their direct effects, the compounds were administered acutely by a nanoinjector prior to measurements of $\mathrm{NO}$ and $\mathrm{ONOO}^{-}$ release from the cells. For combination studies, cells were treated with various $\beta_{3}$-receptor and ATP pathway modulators, VAS2870 or PEG-SOD for 30 minutes prior to treatment with nebivolol.

\section{ATP measurement}

Extracellular ATP was quantified using a luciferinluciferase assay kit (BioAssay Systems, Hayward, CA). The ATP measurement was performed following the supplier's recommendations. Briefly, confluent HUVECs were rinsed and incubated at $37^{\circ} \mathrm{C}$ in EBM medium for 5 minutes in the absence or presence of the various test agents. Aliquots $(100 \mu \mathrm{L})$ of each sample supernatant were then transferred to a white opaque 96-well plate, along with luciferin and luciferase, and then luminescence was measured on a luminometer (BioTek, Winooski, VT). The ATP concentration was obtained using a standard calibration, prepared as recommended in the kit.

\section{Calculations and statistical analysis}

All data are presented as mean \pm standard deviation (SD) of the mean of $\mathrm{n}>3$. Statistical analysis of the mean difference between multiple groups was performed using one-way analysis of variance (ANOVA) with StudentNewman-Keuls multiple comparisons post hoc analysis; and between two groups, using Student's $t$-test. The alpha level for all the tests was 0.05 . A P value $<0.05$ was considered to be statistically significant. All statistical analyses were performed using Origin (v 6.1 for Windows; OriginLab, Northampton, MA) and GraphPad Prism (v. 5.00 for Windows; GraphPad Software, San Diego, CA).

\section{Results}

Using nanonsensor technology, we measured in situ, near-real time $\mathrm{NO}$ and $\mathrm{ONOO}^{-}$released from HUVECs following the acute administration of nebivolol, L-755, 507, 2-MeSATP or ATP over a range of concentrations. Representative amperograms (concentration/current vs. time) collected from endothelial cells treated with nebivolol, L-755,507, 2-MeSATP, and ATP are shown in the Figure 1. A distinctive difference between the slope and peak height of amperograms was observed for both $\mathrm{NO}$ and $\mathrm{ONOO}^{-}$production. The slope of amperograms was used to calculate the rate of $\mathrm{NO}$ and $\mathrm{ONOO}^{-}$generation by endothelial cells after stimulation with nebivolol, L-755,507, 2-MeSATP, and ATP (Figure 2). The kinetics of NO release was relatively slow for nebivolol, with a rate of
$75 \pm 4 \mathrm{nM} / \mathrm{s}$, and significantly faster for L-755,507 (108 \pm $6 \mathrm{nM} / \mathrm{s})$ and 2-MeSATP $(105 \pm 5 \mathrm{nM} / \mathrm{s})$; and very fast for ATP-stimulated NO release $(194 \pm 10 \mathrm{nM} / \mathrm{s})$. The rates for $\mathrm{ONOO}^{-}$followed this same pattern as $\mathrm{NO}$ - lowest rate for nebivolol and the highest for ATP.

As shown in the Figure 3, the maximal NO concentration of $225 \pm 15 \mathrm{nM}$ was observed after stimulation with nebivolol and was the highest among the four agents tested. Surprisingly, $\mathrm{ONOO}^{-}$concentration was the lowest after nebivolol stimulation $(125 \pm 10 \mathrm{nM})$ and the highest after ATP stimulation $(220 \pm 13 \mathrm{nM})$. The maximal $\mathrm{NO}$ and $\mathrm{ONOO}^{-}$concentrations were between that observed for nebivolol and ATP. We applied the ratio of $[\mathrm{NO}]$ and $\left[\mathrm{ONOO}^{-}\right]$concentrations to depict the chemical redox balance between these two molecules in the cellular milieu. A decrease in $[\mathrm{NO}] /\left[\mathrm{ONOO}^{-}\right]$ratio indicates a decrease in the concentration of the cytoprotective $\mathrm{NO}$ and/or an increase in the level of highly oxidative, cytotoxic $\mathrm{ONOO}^{-}$. A ratio of $[\mathrm{NO}] /\left[\mathrm{ONOO}^{-}\right]$below 1.0 is an indicator that the cellular environment is dominated by high oxidative/nitroxidative stress.

Nanosensors provide unique opportunities for the simultaneous measurement of $\mathrm{NO}$ and $\mathrm{ONOO}^{-}$concentration in small volume $\left(\sim 10^{-15} \mathrm{~L}\right)$, at near real-time $\left(10^{-5} \mathrm{~s}\right)$ in close proximity to the cell membrane $(\sim 5 \mu \mathrm{m})$. The ratios of $[\mathrm{NO}] /\left[\mathrm{ONOO}^{-}\right]$are presented in the Figure $3 \mathrm{~B}$. There is a highly significant difference in the $[\mathrm{NO}] /\left[\mathrm{ONOO}^{-}\right]$ balance between nebivolol $(1.80 \pm 0.10)$ and ATP $(0.80 \pm$ $0.08)$. The ratio of $[\mathrm{NO}] /\left[\mathrm{ONOO}^{-}\right]$for $\mathrm{L}^{-7} 755,507$ and 2MeSATP are similar, $1.08 \pm 0.08$ and $1.09 \pm 0.09$ respectively. There is a $40-60 \%$ difference in the $[\mathrm{NO}] /\left[\mathrm{ONOO}^{-}\right]$ balance between nebivolol and 3 other agents tested here.

A very low ratio of $[\mathrm{NO}] /\left[\mathrm{ONOO}^{-}\right]$(lower than one) was observed only after the stimulation of endothelial cells by ATP (Figure 3B). We validated this model of monitoring $[\mathrm{NO}] /\left[\mathrm{ONOO}^{-}\right]$balance in endothelial cells by changing the level of superoxide $\left(\mathrm{O}_{2}^{-}\right)$, the precursor of $\mathrm{ONOO}^{-}$. In the presence of membrane permeable PEGSOD $(400 \mathrm{U} / \mathrm{mL})$, a significant reduction in $\mathrm{ONOO}^{-}$concentration with concomitant increase in the NO level was observed (Figure 4A). This effect was observed for both nebivolol and ATP. A similar effect of the increase in NO and proportional decrease in $\mathrm{ONOO}^{-}$was noticed in the presence of NADPH oxidase inhibitor, VAS2870 $(5 \mu \mathrm{M})$. The Inhibition of the NADPH oxidase increases NO concentration by $20-30 \%$ after stimulation with nebivolol or ATP. This indicates that about $20-30 \%$ of NO produced by the endothelium is consumed by $\mathrm{O}_{2}^{-}$generated by $\mathrm{NADPH}$ oxidase. The source of the remaining $70-80 \%$ of $\mathrm{O}_{2}^{-}$in nebivolol- or ATP-stimulated endothelium is most likely eNOS.

The decrease in $\mathrm{O}_{2}^{-}$had a significant influence on the level of bioavailable $\mathrm{NO}$ and the concentration of $\mathrm{ONOO}^{-}$, as reflected by a significant increase in $[\mathrm{NO}] /$ 

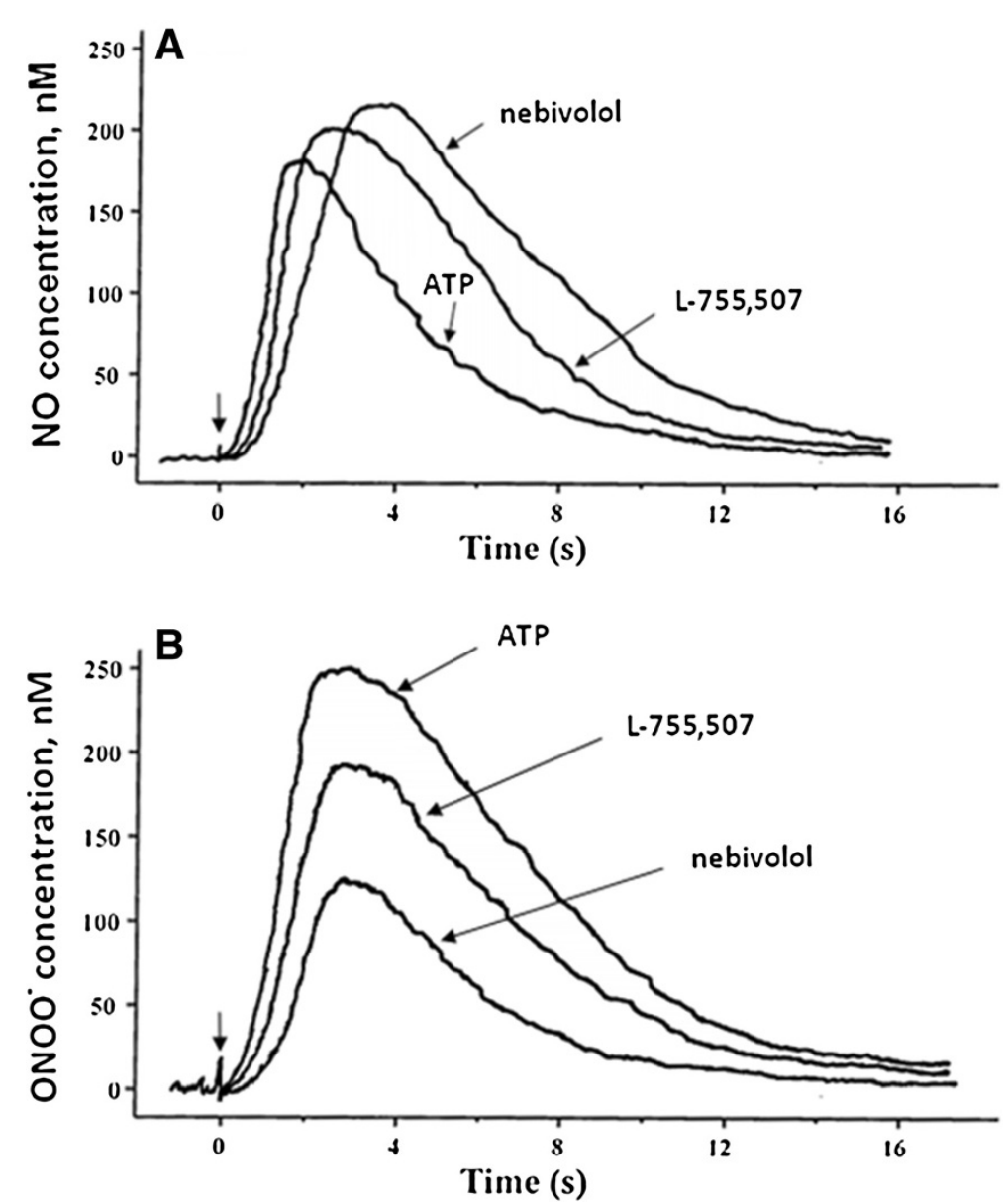

Figure 1 Representative amperograms showing endothelial NO and ONOO- release stimulated with nebivolol, L-755,507, 2-MeSATP, and ATP. NO (A) and ONOO- (B) release from HUVECs were stimulated with nebivolol, ATP, 2-MeSATP, or L-755,507 (each at 1 MM). The amperograms of the 2-MeSATP partially overlaps that of $L-755,507$ and are omitted. NO and ONOO- release were measured with electrochemical nanosensors positioned $5 \pm 2 \mu \mathrm{m}$ from the surface of a single cell. Arrows indicate compound administration.

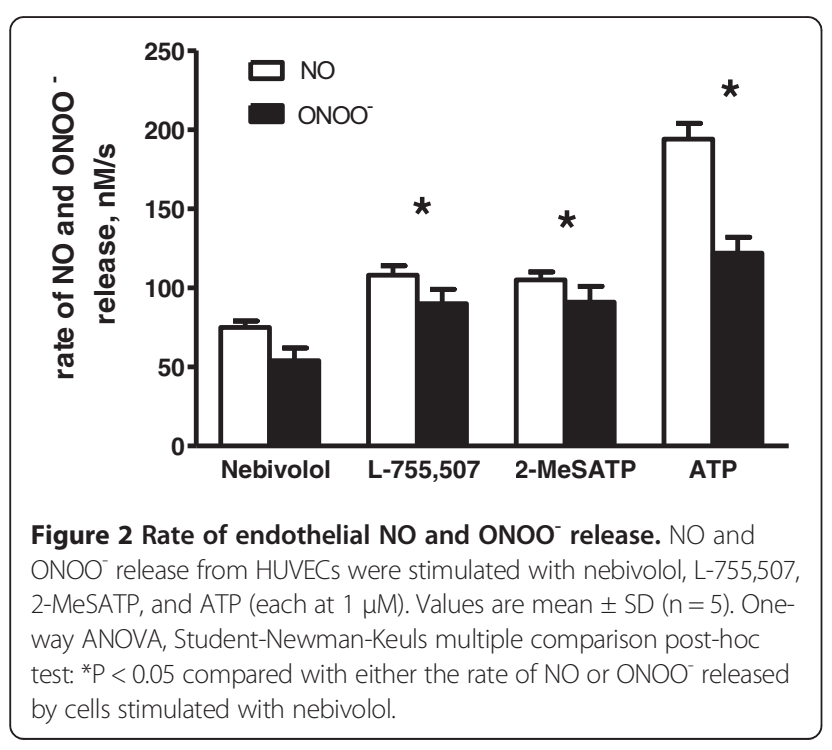

$\left[\mathrm{ONOO}^{-}\right]$ratio (Figure $\left.4 \mathrm{~B}\right)$. A favorable $[\mathrm{NO}] /\left[\mathrm{ONOO}^{-}\right]$ balance increased even further for nebivolol to $4.30 \pm$ 0.21 in the presence of PEG-SOD. Also, in the presence of PEG-SOD, a favorable shift in the $[\mathrm{NO}] /\left[\mathrm{ONOO}^{-}\right]$ balance was observed for ATP.

Nebivolol increased endothelial $\mathrm{NO}$ release in a dosedependent manner (Figure 5A). The effect of nebivolol on ATP concentration released from cells was significant and correlated well with a dose-dependent increase in $\mathrm{NO}$ production (Figure $5 \mathrm{~B})$. The ratio of $[\mathrm{NO}] /\left[\mathrm{ONOO}^{-}\right]$ decreased with the increase of nebivolol concentration (Figure 5C). This correlates well with a fast increase in nebivolol-stimulated ATP component in the overall stimulation process of $\mathrm{NO}$ release.

The relationship between NO bioavailability and ATP production was further tested using modulators of the ATP/purinergic pathway. Each of these agents significantly attenuated the effects of nebivolol on endothelial NO release (Figure 6A). At the specific concentrations 


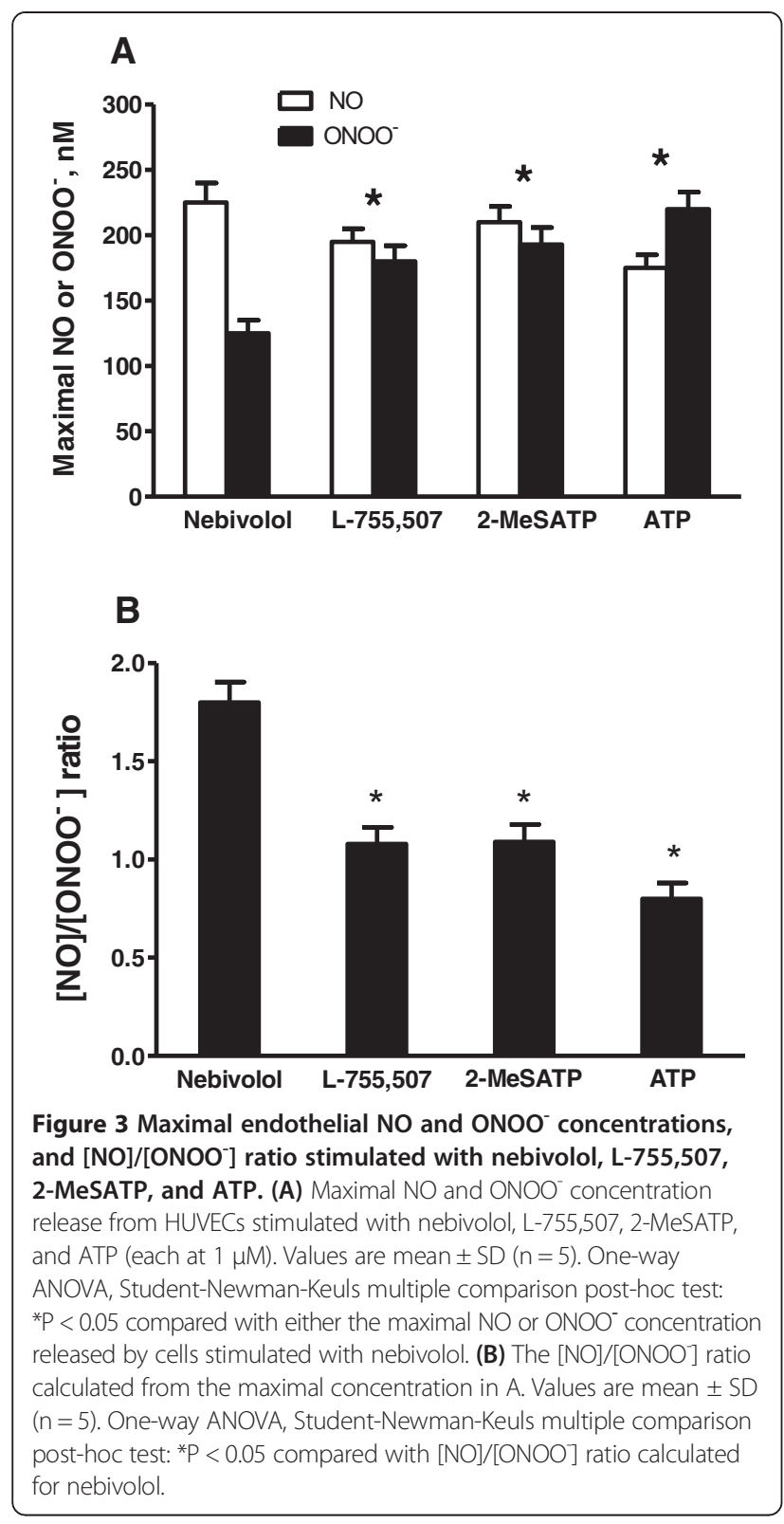

tested, suramin $(10 \mu \mathrm{M})$ and $\mathrm{Gd}^{3+}(200 \mu \mathrm{M})$ inhibited nebivolol-induced NO release by 50 and $60 \%$, respectively. These findings are consistent with the observation that the effects of nebivolol on endothelial-dependent NO release is casually associated with ATP production, especially at higher concentrations of nebivolol. We also measured the effects of nebivolol on endothelial NO release in the presence of $\beta_{3}$-receptor antagonists SR59230A $(1 \mu \mathrm{M})$ or L-748,337 $(3 \mu \mathrm{M})$. Both of these agents reduced the nebivolol-induced $\mathrm{NO}$ release by approximately $50 \%$ (Figure 6A). However, a combination of suramin and SR59230A reduced nebivolol stimulated NO by more than $90 \%$.

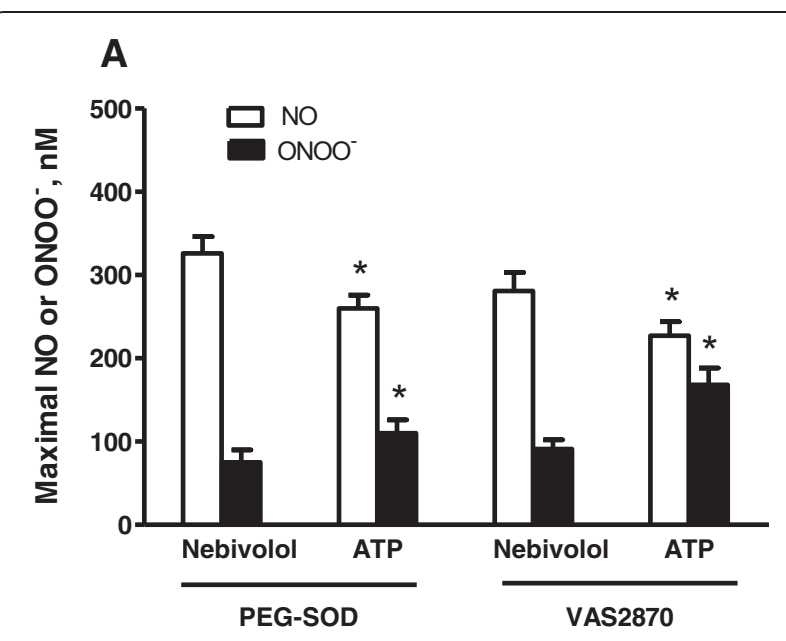

B

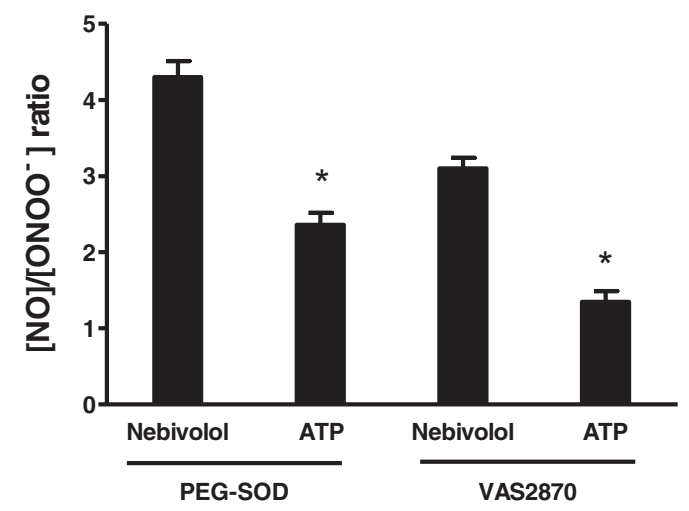

Figure 4 Maximal endothelial NO and ONOO- concentrations, and $[\mathrm{NO}] /\left[\mathrm{ONOO}^{-}\right]$ratio stimulated with nebivolol and ATP following a PEG-SOD and VAS2870 incubation. (A) Maximal NO and $\mathrm{ONOO}^{-}$concentrations stimulated with nebivolol and ATP (each at $1 \mu \mathrm{M}$ ) following a 30-minute incubation of HUVECs with PEG-SOD $(400 \mathrm{U} / \mathrm{mL})$ and VAS2870 $(5 \mu M)$. Values are mean $\pm \mathrm{SD}(\mathrm{n}=5)$. Student's t-test: ${ }^{*} \mathrm{P}<0.05$ compared with nebivolol. (B) The [NO]/ [ONOO'] ratio calculated from the maximal concentration in $A$. Values are mean $\pm S D(n=5)$. Student's t-test: * $P<0.05$ compared with $[\mathrm{NO}] /\left[\mathrm{ONOO}^{-}\right]$balance calculated for nebivolol.

\section{Discussion}

The key finding from this study is that nebivololstimulated NO release from human endothelial cells is multipathway and slow. This slow process preserves eNOS coupling and leads to a high production of bioavailable $\mathrm{NO}$ and low production of $\mathrm{ONOO}^{-}$. The slow kinetics and dynamics of $\mathrm{NO}$ generation is a significant factor in the maintaining of the highly favorable balance between $[\mathrm{NO}]$ and $\left[\mathrm{ONOO}^{-}\right]$concentrations in the endothelium. The favorable kinetics of NO release, combined with $\mathrm{O}_{2}^{-}$scavenging by nebivolol, may help to explain the pleiotropic effect of nebivolol on the cardiovascular system observed in clinical studies. The 


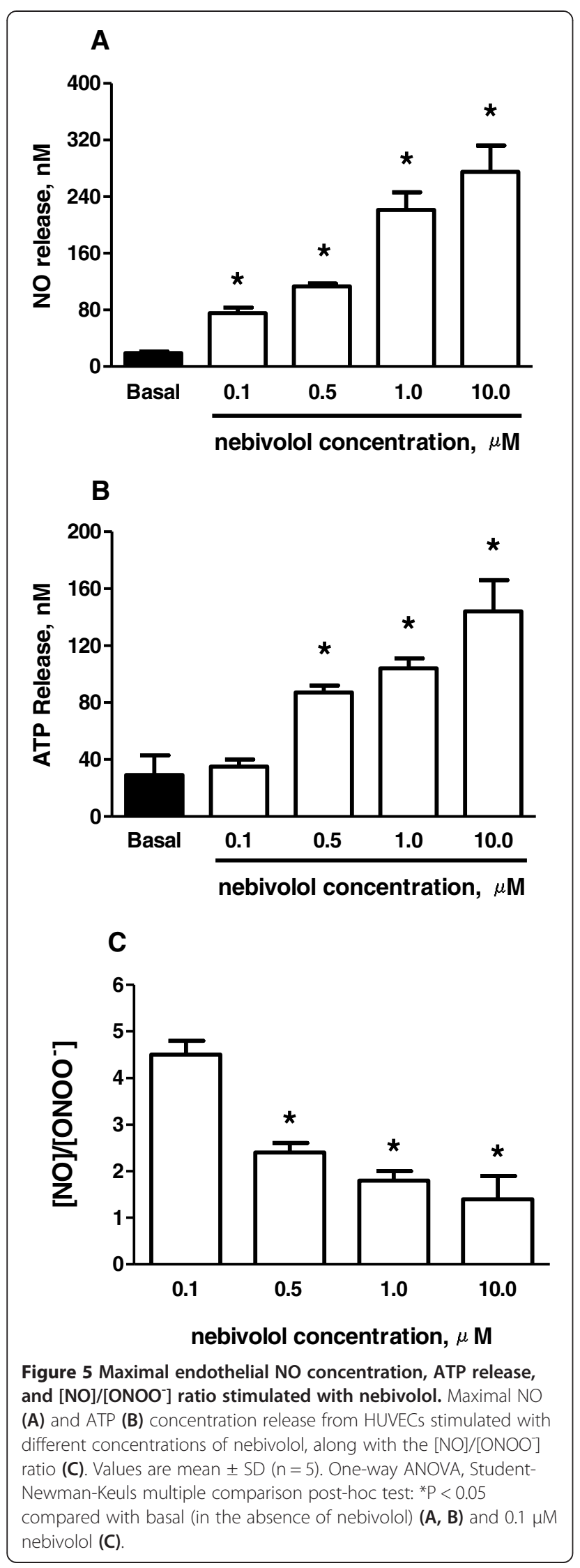

rate of NO release by nebivolol is slower than that observed for the other three agents presented in this study (ATP, L-755,507, and 2-MeSATP). These three agents produced comparable NO concentrations with nebivolol, however, excessive and rapid NO production stimulated by these agents eventually leads to uncoupling of eNOS (rapid depletion of substrates and/or cofactors for $\mathrm{NO}$ production). The uncoupled eNOS is an efficient generator of $\mathrm{O}_{2}^{-}$in one electron transfer reduction of oxygen. Therefore, uncoupled eNOS can produce, sequentially, both $\mathrm{NO}$ and $\mathrm{O}_{2}^{-}$. $\mathrm{NO}$ and $\mathrm{O}_{2}^{-}$generated in close proximity by eNOS can react rapidly in a diffusion controlled reaction to produce $\mathrm{ONOO}^{-}$. The studies with VAS2870 also elucidated that the second major source of $\mathrm{O}_{2}^{-}$in the endothelium during the stimulation of $\mathrm{NO}$ release by nebivolol is NADPH oxidase. Our study shows that after the stimulation of endothelial cells with nebivolol, the contribution of NADPH oxidase to the pool of $\mathrm{O}_{2}^{-}$, and subsequently the pool of $\mathrm{ONOO}^{-}$is about $20-30 \%$, while about $70-80 \%$ of $\mathrm{O}_{2}^{-}$and $\mathrm{ONOO}^{-}$comes from uncoupled eNOS. NADPH oxidase contribution to the pool of $\mathrm{O}_{2}^{-}$and $\mathrm{ONOO}^{-}$after stimulation with ATP is about 30-35\% with eNOS contributing $65-70 \%$. In addition to the favorable kinetics of $\mathrm{NO}$ release, nebivolol may also increase NO bioavailability through non-receptor-mediated mechanisms, such as conveying antioxidant benefits of the endothelium. Nebivolol has been shown to scavenge $\mathrm{O}_{2}^{-}$independent of $\beta_{3}$-receptor blockade in animal and cell based models of cardiovascular diseases $[13,17,20,21]$. These effects are attributed to its specific interactions with plasma membrane and its efficiency as a chain-breaking antioxidant [13,25]. Nebivolol has also been shown to interact with enzymatic sources of oxygen radicals such as NADPH oxidase $[21,22]$. This correlates well with our data showing lower generation of $\mathrm{O}_{2}^{-} / \mathrm{ONOO}^{-}$by $\mathrm{NADPH}$ oxidase than eNOS after stimulation with nebivolol.

The scavenging properties of nebivolol cannot alone explain the low level of $\mathrm{ONOO}^{-}$and slow kinetics of nebivolol stimulated NO production. The results of our study suggest that nebivolol increases NO release in the human endothelium through a complementary mechanism involving 33 -receptor, ATP autocrine and/or paracrine, and P2Y-receptor activation. Two different $\beta_{3}$-receptor antagonists (SR59230A and L-748,337) were discovered to significantly reduce nebivolol-induced NO release in HUVECs. However, these $\beta_{3}$-receptor antagonists reduced NO production only by about $50 \%$. A blockage with $\mathrm{Gd}^{3+}$ of mechanosensitive ATP channels of HUVECs reduced NO production by $60 \%$, indicating a direct involvement of extracellular ATP in the stimulation process. Finally, in the presence of both antagonists of the P2Y-receptor, suramin, and $\beta_{3}$-receptor antagonist, SR59230A, NO concentration decreased by more than $90 \%$. 
A

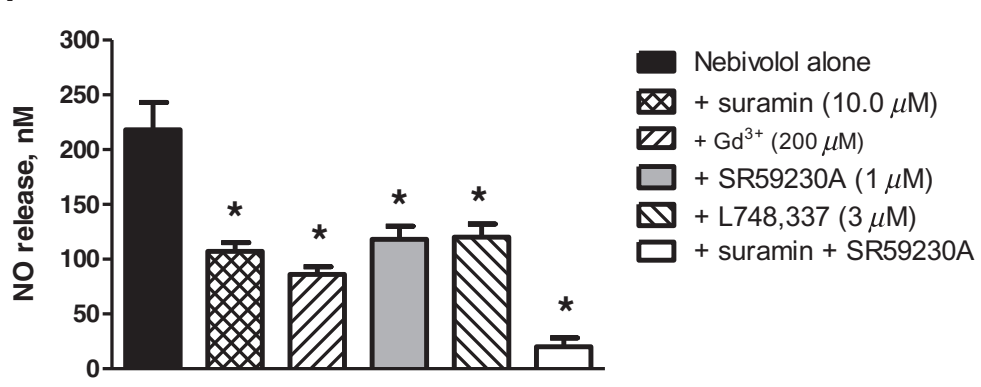

$\mathbf{B}$

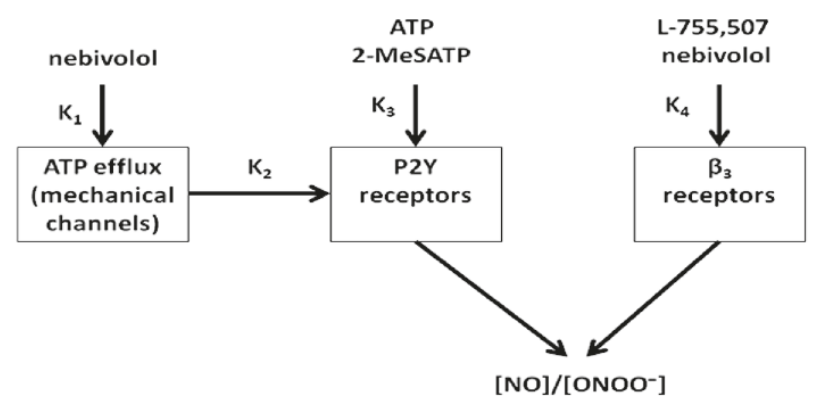

C

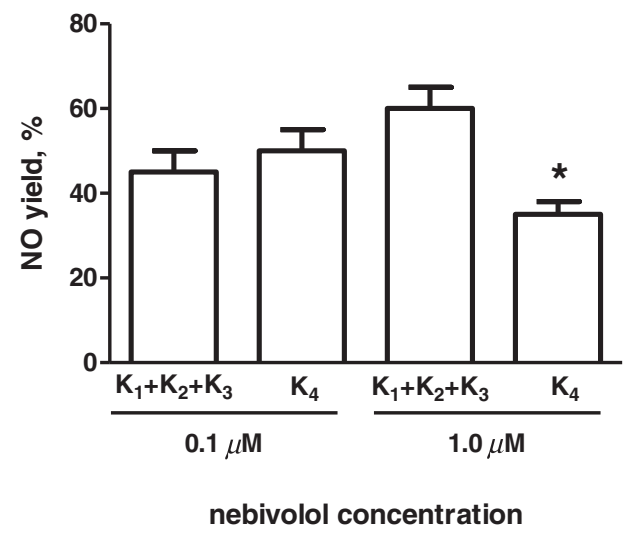

Figure 6 Major pathways involved in nebivolol-stimulated NO and ONOO- generation, and maximal endothelial NO concentration stimulated with nebivolol alone or following an incubation with several modulators. (A) Maximal NO concentration release from HUVECS stimulated with nebivolol $(1 \mu \mathrm{M})$. Cells were also incubated with suramin $(10 \mu \mathrm{M}), \mathrm{Gd}^{3+}(200 \mu \mathrm{M})$, SR59230A $(1 \mu \mathrm{M}), \mathrm{L}-748,337(3 \mu \mathrm{M})$ and suramin + SR59230A for 30 minutes and NO release was stimulated with nebivolol $(1 \mu M)$. Values are mean \pm SD $(n=5)$. One-way ANOVA, Student-NewmanKeuls multiple comparison post-hoc test: ${ }^{*} \mathrm{P}<0.05$ compared with nebivolol alone. (B) Nebivolol-stimulated generation of $\mathrm{NO}^{2}$ and $\mathrm{ONOO}^{-}$involves at least two major pathways and several steps. (C) At low nebivolol concentration, $\mathrm{K}_{4}$ will be more determinant than at higher concentration. Values are mean $\pm S D(n=5)$. Student's t-test: *P $<0.05$ compared with $K_{1}+K_{2}+K_{3}$.

Our findings in this study argue for the involvement of $\beta_{3}$-receptors in eNOS activation and NO release in human endothelial cells stimulated by nebivolol. A role for $\beta_{3}$-receptors in nebivolol-induced NO release was previously demonstrated in human heart ventricular tissue and coronary microarteries [19]. Nebivolol was shown to activate cardiac $\beta_{3}$-receptors in a manner similar to that of the selective $\beta_{3}$-receptor agonist, BRL 37344, both of which resulted in a change in ventricular contraction attributed to NO release. The negative inotropic effects of nebivolol were modified by pretreatment with L-748, 337 , but not with nadolol, a nonselective $\beta_{2} / \beta_{3}$-receptor antagonist [19]. These specific receptor-mediated effects of nebivolol on NO metabolism may contribute to favorable changes in vascular hemodynamic properties and calcium regulation given the relative distribution of $\beta_{1}$ and $\beta_{3}$-receptors in the failing heart. Clinical support for such potential benefit was demonstrated in a randomized trial of elderly patients with documented heart failure [26]. Nebivolol was also shown in another study to 
increase vasodilation in coronary microarteries essential for the regulation of coronary resistance and perfusion reserve [18]. Endothelial-dependent vasodilation was not reproduced with nebivolol in mice deficient for $\beta_{3}$-receptors [18]. Nebivolol also failed to induce neocapillary tube formation in animals deficient in either $\beta_{3}$-receptor or eNOS expression [18]. Another recent study showed that nebivolol increased levels of endothelial progenitor cells, promoted angiogenesis, and reversed left ventricular dysfunction in mice with extensive myocardial infarction [20]. The vasodilation effects of nebivolol could only be partially blocked with a specific $\beta_{3}$-adrenergic receptor antagonist [20]. The data presented in our work established an important connection between the cardioprotective effects of nebivolol and its $\beta_{3}$-mediated, ATP-mediated effects on eNOS function.

The results of this study also suggest a role for the ATP autocrine and/or paracrine pathway in the activation of eNOS. It was found that the mechanosensitive ATP channel blocker, $\mathrm{Gd}^{3+}$, inhibited nebivolol-induced NO release by $60 \%$. Moreover, the rate of NO stimulation with ATP is much faster than the stimulation with nebivolol. Therefore, we concluded that a rate determining factor in the kinetics of nebivolol-stimulated $\mathrm{NO}$ may be the ATP efflux from endothelial cells. The delivery of ATP from intracellular to extracellular space will require a buildup of the gradient of concentration, passage through mechanical channels and diffusion to receptors on the membrane surface. These delivery processes, based on efflux and diffusion, will be much slower than the direct high gradient diffusion of ATP to membrane receptors from an outer solution of ATP.

Extracellular ATP promotes vascular relaxation through the activation of $\mathrm{P} 2 \mathrm{Y}$ receptors and the subsequent stimulation of eNOS and cytosolic guanylate cyclase [10]. Exogenous ATP has been shown to promote NO release from Wister-Kyoto rat glomerular endothelial cells with kinetic properties similar to those of nebivolol [17]. Inhibition of ATP efflux with $\mathrm{Gd}^{3+}$, an inhibitor of stretchactivated channels, also reduced the effects of nebivolol [17]. We demonstrated that a pretreatment of cells with $\mathrm{Gd}^{3+}$ decreased the ability of nebivolol-induced endothelial NO release. This may suggest that nebivolol itself may be linked to opening of mechanosensitive ATP channels.

It appears from this study that the kinetics of $\mathrm{NO}$ production by eNOS is crucial in maintaining a favorable balance between $[\mathrm{NO}] /\left[\mathrm{ONOO}^{-}\right]$concentrations. A rapid stimulation may produce high level of $\mathrm{NO}$ but also a high level of $\mathrm{ONOO}^{-}$. Therefore, the rapid generation of $\mathrm{NO}$ accompanied by high $\mathrm{ONOO}^{-}$cancels the beneficial effect of $\mathrm{NO}$ and imposes a deleterious effect of $\mathrm{ONOO}^{-}$induced nitroxidative stress with severe side effect for the endothelium. $\mathrm{NO}$ and $\mathrm{ONOO}^{-}$stimulation by cerivastatin is a good example of this kind of "non-favorable kinetics" of NO release [27]. A potentially excellent pleiotropic effect of cerivastatin was compromised by the negative effect of high $\mathrm{ONOO}^{-}$generated by this drug. This negative side effect of cerivastatin on the cardiovascular system was the forced withdrawal of this otherwise excellent drug from the pharmaceutical market.

\section{Limitations}

HUVECs were used in this study as the sole source of endothelial cells. Further studies will be required to confirm these findings using other sources of endothelial cells.

\section{Conclusions}

We propose that nebivolol-stimulated generation of $\mathrm{NO}$ and $\mathrm{ONOO}^{-}$involves at least two major pathways and several steps (Figure 6B). One of this pathways involves a stimulation of intracellular ATP efflux through mechanical channels $\left(\mathrm{K}_{1}\right)$, diffusion of extracellular ATP to P2Y receptors $\left(\mathrm{K}_{2}\right)$, and stimulation of P2Y receptors by ATP $\left(K_{3}\right)$ followed by the release of $\mathrm{NO}$ and $\mathrm{ONOO}^{-}$. We propose that this pathway involving many steps is a rate determining factor in $\mathrm{NO}$ and $\mathrm{ONOO}^{-}$production after stimulation with nebivolol. The other pathway, through $\beta_{3}$ receptors $\left(\mathrm{K}_{4}\right)$ is faster and the rate of $\mathrm{NO}$ and $\mathrm{ONOO}^{-}$release comparable with that of $\mathrm{K}_{3}$. Therefore, the yield of NO produced by each pathway will vary with the concentration of nebivolol. At low nebivolol concentration, $\mathrm{K}_{4}$ pathway will be more determinant than at higher concentration (Figure 6C).

The results of this study provide additional insights into the cellular basis for nebivolol-induced NO release in human endothelial cells. The ability of nebivolol to stimulate NO release appears to be independent of its selective $\beta_{1}$-blockade properties and dependent on stimulation of $\beta_{3}$-receptors and ATP-mediated stimulation of P2Y-purinergic receptors. It seems to be also linked to direct opening of mechanosensitive ATP channels. A multistep stimulation of NO release is relatively slow and the production of NO does not significantly influence the supply of substrates or cofactors to eNOS, maintaining its relative high degree of coupling. The coupled eNOS can produce high NO concentration and low $\mathrm{ONOO}^{-}$leading to a highly beneficial effect of nebivolol in the treatment of dysfunctional endothelium in cardiovascular diseases.

\footnotetext{
Competing interests

Dr Mason received an independent research grant in support of this study from Forest Laboratories. All other authors have no conflicts of interest to disclose.

Authors' contributions

RPM and TM designed the study. JJC, DS, and KM performed the experimental work. RPM, RFJ, JJC, and TM carried out the analyses, interpreted the data, drafted the manuscript and critically reviewed it. All authors read and approved the final manuscript.
} 


\section{Acknowledgements}

Financial support was provided by the Marvin White Endowment Fund at Ohio University. A special thanks to Forest Laboratories for providing nebivolol, and to Collin Arocho and Paula Hale for their assistance in the preparation of this manuscript. This investigation was conducted in a facility constructed with support from Research Facilities Improvement Program Grant Number C06 RR-014575-01 from the National Center for Research Resources, National Institutes of Health.

\section{Author details}

'Cardiovascular Division, Department of Medicine, Brigham and Women's Hospital, Harvard Medical School, 02115 Boston, MA, USA. ${ }^{2}$ Elucida Research LLC, 01915 Beverly, MA, USA. ${ }^{3}$ Department of Chemistry and Biochemistry, Ohio University, 45701 Athens, OH, USA.

Received: 23 July 2013 Accepted: 24 September 2013

Published: 28 September 2013

\section{References}

1. Ignarro LJ, Buga GM, Wood KS, Byrnes RE, Chaudhuri G: Endotheliumderived relaxing factor produced and released from artery and vein is nitric oxide. Proc Natl Acad Sci U S A 1987, 84:9265-9269.

2. Rees DD, Palmer RM, Moncada S: The role of endothelium-derived nitric oxide in the regulation of blood pressure. Proc Natl Acad Sci U S A 1989, 86:3375-3378

3. Kojda G, Harrison DG: Interactions between NO and reactive oxygen species: pathophysiological importance in atherosclerosis, hypertension diabetes and heart failure. Cardiovas Res 1999, 43:562-571.

4. Mizuno Y, Jacob RF, Mason RP: Effects of calcium channel and reninangiotensin system blockade on intravascular and neurohormonal mechanisms of hypertensive vascular disease. Am J Hypertens 2008, 21:1076-1085

5. Mizuno $Y$, Jacob RF, Mason RP: Advances in pharmacologic modulation of nitric oxide in hypertension. Curr Cardiol Rep 2010, 12:472-480

6. Mason RP, Jacob RF, Kubant R, Ciszewski A, Corbalan JJ, Malinski T: Dipeptidyl peptidase-4 inhibition with saxagliptin enhanced nitric oxide release and reduced blood pressure and SICAM-1 levels in hypertensive rats. J Cardiovasc Pharmacol 2012, 60:467-473.

7. Corriden R, Insel PA: Basal release of ATP: an autocrine-paracrine mechanism for cell regulation. Sci Signal 2010, 3:re1-re25.

8. Dominiczak AF, Quilley J, Bohr DF: Contraction and relaxation of rat aorta in response to ATP. Am J Physiol 1991, 261:H243-H251.

9. Mathie RT, Ralevic V, Alexander B, Burnstock G: Nitric oxide is the mediator of ATP-induced dilatation of the rabbit hepatic arterial vascular bed. $\mathrm{Br} J$ Pharmacol 1991, 103:1602-1606.

10. Jankowski M, Szczepanska-Konkel M, Kalinowski L, Angielski S: Cyclic GMPdependent relaxation of isolated rat renal glomeruli induced by extracellular ATP. J Physiol 2001, 530:123-130.

11. Bowman AJ, Chen CP, Ford GA: Nitric oxide mediated venodilator effects of nebivolol. Br J Clin Pharmacol 1994, 38:199-204.

12. Ignarro LJ: Experimental evidences of nitric oxide-dependent vasodilatory activity of nebivolol, a third-generation beta-blocker. Blood Press 2004, 1:2-16.

13. Mason RP, Kubant R, Jacob RF, Walter MF, Boychuk B, Malinski T: Effect of nebivolol on endothelial nitric oxide and peroxynitrite release in hypertensive animals: Role of antioxidant activity. J Cardiovas Pharmacol 2006, 48:862-869.

14. Cockcroft JR: Exploring vascular benefits of endothleium-derived nitric oxide. Am J Hypertens 2005, 18:177S-183S

15. Georgescu A, Pluteanu F, Flonta ML, Badila E, Dorobantu M, Popov D: The cellular mechanisms involved in the vasodilator effect of nebivolol on the renal artery. Eur J Pharmacol 2005, 508:159-166.

16. Tzemos N, Lim PO, MacDonald TM: Nebivolol reverses endothelial dysfunction in essential hypertension: A randomized, double-blind, crossover study. Circulation 2001, 104:511-514.

17. Kalinowski L, Dobrucki LW, Szczepanska-Konkel M, Jankowski M, Martyniec L, Angilieski S, Malinski T: Third-generation b-blockers stimulate nitric oxide release from endothelial cells through ATP efflux: a novel mechanism for antihypertensive action. Circulation 2003, 107:2747-2752.

18. Dessy C, Saliez J, Ghisdal P, Daneau G, Lobysheva II, Frerart F, Belge C, Inaoui K, Noirhomme P, Feron O, Balligand JL: Endothelial beta3- adrenoreceptors mediate nitric oxide-dependent vasorelaxation of coronary microvessels in response to the third-generation beta-blocker nebivolol. Circulation 2005, 112:1198-1205.

19. Rozec B, Erfanian M, Laurent K, Trochu JN, Gauthier C: Nebivolol, a vasodilating selective beta(1)-blocker, is a beta(3)-adrenoceptor agonist in the nonfailing transplanted human heart. J Am Coll Cardiol 2009, 53:1532-1538.

20. Sorrentino SA, Doerries C, Manes C, Speer T, Dessy C, Lobysheva I, Mohmand W, Akbur R, Bahlmann F, Besler C, Schaefer A, Hilfiker-Kleiner D, Luscher TF, Balligand JL, Drexler H, Landmesser U: Nebivolol exerts beneficial effects on endothelial function, early endothelial progenitor cells, myocardial neovascularization, and left ventricular dysfunction early after myocardial infarction beyond conventional beta1-blockade. J Am Coll Cardiol 2011, 57:601-611.

21. Mason RP, Kalinowski L, Jacob RF, Jacoby AM, Malinski T: Nebivolol reduces nitroxidative stress and restores nitric oxide bioavailability in endothelium of black Americans. Circulation 2005, 112:3795-3801.

22. Mollnau H, Schulz E, Daiber A, Baldus S, Oelze M, August M, Wendt M, Walter U, Geiger C, Agrawal R, Kleschyov AL, Meinertz T, Munzel T: Nebivolol prevents vascular NOS III uncoupling in experimental hyperlipidemia and inhibits NADPH oxidase activity in inflammatory cells. Arterioscler Thromb Vasc Biol 2003, 23:615-621.

23. Mason RP, Kubant R, Jacob RF, Malinski P, Huang X, Louka FR, Borowic J, Mizudo $Y$, Malinski T: Loss of arterial and renal nitric oxide bioavailability in hypertensive rats with diabetes. Am J Hypertens 2009, 22:1160-1166.

24. Malinski T, Taha Z: Nitric oxide release from a single cell measured in situ by a porphyrinic-based microsensor. Nature 1992, 358:676-678.

25. Janssen PM, Zeitz O, Hasenfuss G: Transient and sustained impacts of hydroxyl radicals on sarcoplasmic reticulum function: protective effect of nebivolol. Eur J Pharmacol 1999, 366:223-323.

26. Flather MD, Shibata MC, Coats AJ, Van Veldhuisen DJ, Parkhomenko A, Borbola J, Cohen-Solal A, Dumitrascu D, Ferrari R, Lechat P, Soler-Soler J, Tavazzi L, Spinarova L, Toman J, Bohm M, Anker SD, Thompson SG, PooleWilson PA: Randomized trial to determine the effect of nebivolol on mortality and cardiovascular hospital admission in elderly patients with heart failure (SENIORS). Eur Heart J 2005, 26:215-225.

27. Kalinowski L, Dobrucki LW, Brovkovych V, Malinski T: Increased nitric oxide bioavailability in endothelial cells contributes to the pleiotropic effect of cerivastatin. Circulation 2002, 105:933-938.

\section{doi:10.1186/2050-6511-14-48}

Cite this article as: Mason et al:: The favorable kinetics and balance of nebivolol-stimulated nitric oxide and peroxynitrite release in human endothelial cells. BMC Pharmacology and Toxicology 2013 14:48.

\section{Submit your next manuscript to BioMed Central and take full advantage of:}

- Convenient online submission

- Thorough peer review

- No space constraints or color figure charges

- Immediate publication on acceptance

- Inclusion in PubMed, CAS, Scopus and Google Scholar

- Research which is freely available for redistribution
C Biomed Central 